EOMmUn: Communication et organisation

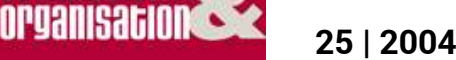

Les vallées : sens, territoires et signes

\title{
Avec Jean-Luc ANSEL Directeur de la Cosmetic Valley
}

Florence Hénon

\section{(2) OpenEdition}

12 Journals

Édition électronique

URL : http://journals.openedition.org/communicationorganisation/2967

DOI : 10.4000/communicationorganisation.2967

ISSN : $1775-3546$

Éditeur

Presses universitaires de Bordeaux

Édition imprimée

Date de publication : 2 octobre 2004

ISSN : 1168-5549

Référence électronique

Florence Hénon, «Avec Jean-Luc ANSEL Directeur de la Cosmetic Valley », Communication et organisation [En ligne], 25 | 2004, mis en ligne le 27 mars 2012, consulté le 01 mai 2019. URL : http:// journals.openedition.org/communicationorganisation/2967; DOI : 10.4000/ communicationorganisation.2967

Ce document a été généré automatiquement le 1 mai 2019.

(c) Presses universitaires de Bordeaux 


\title{
Avec Jean-Luc ANSEL Directeur de la Cosmetic Valley
}

\author{
Florence Hénon
}

1 Premier réseau français et mondial d'industriels de la filière Parfums et Cosmétiques, la Cosmetic Valley regroupe, à Chartres et dans le département d'Eure-et-Loir, une concentration impressionnante d'entreprises, la plus forte densité d'établissements de ce secteur. Près de 100 entreprises et 6000 professionnels assurent une grande partie de la production de l'industrie du luxe et de la beauté. Cela représente $70 \%$ des entreprises de la filière.

2 Cette association professionnelle se crée en 1994, présidée par Jean-Paul Guerlain et dirigée par Jean-Luc Ansel, lui-même directeur de Polepharma et du CODEL (Comité de Développement Economique d'Eure-et-loir) et elle rassemble les grands noms comme Guerlain, Yves Saint Laurent, Paco Rabanne, Dior etc..

3 Communication et Organisation (C\&0) : pourquoi avoir créé la Cosmetic Valley?

4 Pour fédérer les gens entre eux. Mettre en place un réseau de sous-traitants, pour que les petites entreprises vivent et ne disparaissent pas et avec eux un savoir-faire etc.. c\& 0 : quel est l'historique de l'association?

6 C'est une histoire d'amitié et la volonté de deux hommes : Jean-Paul Guerlain et moi, de monter un réseau dans lequel tout le monde serait gagnant. En 1974, Jean-Paul Guerlain installe sa production à Chartres, précédemment localisée à Courbevoie. A partir de là, cela fait boule de neige, en 1976 Paco Rabanne etc.. Et puis, cela fait partie des missions du Codel : créer des emplois, implanter des entreprises et animer des réseaux d'entreprises. Le Codel a joué et joue toujours un rôle important.

$7 \quad C \& Q$ : pourquoi avoir choisi une pivoine connue logo?

8 Au départ, ce devait être une rose mats notre choix s'est porté sur la pivoine. C'est un symbole chinois qui signifie bonheur. C'est très positif et la fleur est odorante. Et puis, c'est plus original, charnel et esthétique. 
Une solidarité, une grande solidarité entre les sous-traitants. Ils se passent du travail entre eux. Un respect et un code moral forment les bases de cette association et ils sont appliqués. De plus, pour se vendre et être reconnu, c'est plus facile. La proximité géographique joue aussi beaucoup, elle permet de trouver sur place la main d'œuvre, les produits, tout.

11 C\&O: $\boldsymbol{y}$ a-t-il d'autres réseaux au sein du codel? Nous avons deux autres réseaux: Perchebois et Polepharma. Perchebois est une association, située à Senonches, une filière qui regroupe les acteurs des métiers du bois et de la forêt. L'objectif est dévaloriser leur savoir-faire, leur tradition et de créer une dynamique autour d'une charte de qualité. Polepharma, créée en 2002 à Dreux, représente le réseau pharmaceutique. Plus de 120 établissements de cette filière sont installés dans un rayon de $100 \mathrm{~km}$ autour de Dreux. C'est le même principe que la Cosmetic Valley mais pour le domaine pharmaceutique. Pour l'ensemble de ces trois réseaux, le Codel a énormément aidé. par mois qui permet à tout le monde d'être au courant des dernières nouveautés; les salons qui nous mobilisent beaucoup et qui permet d'être présent dans la majorité des rencontres internationales; les visites d'usine participent à une meilleure connaissance les uns des autres et les rendez-vous thématiques avec conférences et tables rondes, une fois par trimestre.

\section{C\&0 : quels sont les éléments forts de votre politique externe de communication?}

Depuis trois ans, la semaine du parfum existe à Chartres, en septembre, en même temps que Cosmetech. (Test l'occasion de faire découvrir au grand public les senteurs, de développer les sens olfactifs, de proposer des visites, des expositions, une vente aux enchères de flacons de collection, un salon des collections parfumées etc..

17 Nous organisons tous les ans à la même période pendant deux jours Cosmetech Meetings. Il s'agit d'initier et de faciliter des rencontres $B$ to $B$ entre professionnels par l'intermédiaire d'une convention internationale d'affaires de la parfumerie et des cosmétiques. Cette formule plaît car elle privilégie les contacts personnalisés et la confidentialité. Tous les grands prestataires s'y trouvent; en même temps et sur le même lieu se déroule la convention «Chiminov» qui concerne le monde de la chimie fine et à Dreux, à trente minutes de Chartres, celle de Process Pharma, pour les médicaments. Les visiteurs peuvent ainsi cumuler des rencontres professionnelles complémentaires. Rendez-vous préprogrammées et ciblés, des conférences; notre équipe travaille pendant six mois à ces conventions d'affaires et elle prospecte, sélectionne les professionnels et connaît bien chaque participant. C'est un peu du sur mesure.

19 Assez positif même s'il reste encore des choses à faire, bien-sûr. Nous avons régulièrement de nouveaux adhérents et l'international marche très bien. 